\title{
EXUMANDO ROSAS, PROCURANDO (POR) SÍMBOLOS A REVISTA ROSA CRUZ (1901 E 1904)
}

\author{
Fernando Floriani Petry \\ Université de Lyon
}

RESUMO: Este artigo, decorrente das reflexóes iniciadas durante o mestrado em literatura realizado no Núcleo de Estudos Literários e Culturais da Universidade Federal de Santa Catarina / NELIC - UFSC, apresenta algumas das diferentes leituras possiveis para a revista simbolista Rosa-Cruz, publicada nos anos de 1901 e 1904 no Rio de Janeiro. Bastante desconhecida na historiografia literária brasileira, tem-se até hoje uma única chave de leitura da revista: um veículo de homenagem à Cruz e Sousa. A proposta deste artigo é discorrer sobre outros possíveis modos de se ler a revista, partindo de uma análise do seu título e dos diferentes grupos de autores que por ela circularam.

PALAVRAS-CHAVE: Revista Rosa-Cruz. Homenagem. Vida literária.

\section{EXHUMING ROSES, LOOKING (FOR) SYMBOLS ROSA-CRUZ (1901 AND 1904)}

ABSTRACT: This article, a result of the reflections initiated during the Master degree in Literature made at NELIC - Núcleo de Estudos Literários e Culturais at the Universidade Federal de Santa Catarina UFSC, presents some of the many different ways of reading the symbolist magazine Rosa-Cruz, published in 1901 and 1904, in Rio de Janeiro, Brazil. Almost unknown by the literary historiography in Brazil, we have until today a unique way of reading the magazine: as a vehicle of tribute to Cruz e Sousa. The objective of this article is to discuss other ways of reading the magazine, starting with an analysis of the title Rosa-Cruz and advancing by the different groups of authors published by the magazine.

KEYWORDS: Rosa-Cruz magazine. Tribute. Literary life.

Fernando Floriani Petry é professor no Departamento de Português da Universidadede Lyon 2. 


\title{
EXUMANDO ROSAS, PROCURANDO (POR) SÍMBOLOS A REVISTA ROSA CRUZ (1901 E 1904)
}

\author{
Fernando Floriani Petry
}

Cassiano Tavares Bastos proferiu, em 24 de setembro de 1921, na última das quatro vesperais literárias organizadas pelo escritor Adelino de Magalhães, realizadas na Biblioteca Nacional, a fala Como surgiram os místicos da "RosaCruz". Publicado pela primeira vez no Jornal do Comércio, de 14 de março de 1937, o texto recebeu modificações e foi reunido com outros ensaios de Tavares Bastos no livro O simbolismo no Brasil e outros escritos, publicado pela livraria São José, em 1969. Em seu ensaio, o mais jovem membro da revista Rosa-Cruz afirma que

\begin{abstract}
Num tempo que já vai longe, floresceu aqui no Rio um pequeno grupo de jovens intelectuais que, fiéis admiradores de Cruz e Sousa, tomaram a si o piedoso encargo de manter, sempre viva, entre os contemporâneos, a memória sagrada do Dante Negro. Para esse fim, reuniram-se uma bela tarde à mesa do tradicional café da rua Gonçalves Dias e resolveram fundar uma revista literária que, de fato, apareceu e se chamou misticamente Rosa-Cruz. ${ }^{1}$
\end{abstract}

Esse pequeno grupo de intelectuais, sob a direção de Saturnino de Meirelles, publicou a revista Rosa-Cruz, objeto primeiro desse estudo, nos anos de 1901 e 1904, podendo ser, assim, dividida em duas fases. A primeira fase da revista constitui-se de quatro números, de junho a setembro de 1901. Já na segunda fase são três fascículos, de julho a setembro de $1904 .^{2}$ Vale notar que Tavares Bastos aponta um pequeno grupo de intelectuais, jovens, que em uma bela tarde resolveram fundar uma revista em homenagem. Ou seja, mesmo acusando uma formação, um grupo, a revista Rosa-Cruz não surge como um projeto planejado de futuro, uma manifestação de um movimento, um baluarte de uma estética. A revista Rosa-Cruz já nasce com a particularidade de ser

\footnotetext{
${ }^{1}$ BASTOS, Cassiano Tavares. Como surgiram os místicos da "Rosa-Cruz". O simbolismo no Brasil e outros escritos. Rio de Janeiro: Livraria São José, 1969, p. 07.

${ }^{2}$ A diferenciação entre número e fascículo é da própria revista, levando a entender que o próprio editor reconhece nela suas duas fases.
} 
Janus. De estar voltada para trás, enquanto homenagem; e projetada à frente, enquanto uma revista de um jovem grupo, publicando seus primeiros textos.

A redação da revista Rosa-Cruz, durante a sua primeira fase, estava situada à Rua 07 de Setembro, número 157. Já na segunda fase, mudou-se para a Praça Tiradentes, número 83 , ambas na cidade do Rio de Janeiro e a quatro quadras de distância da Praça da República. Uma breve excursão histórica nos remete ao Rio de Janeiro, capital de um Brasil recém república, atravessando uma série de reformas urbanísticas durante a administração do prefeito Pereira Passos e do presidente da república Rodrigues Alves. O grande projeto de saneamento e modernização da cidade do Rio de Janeiro teve apoio também na figura do Dr. Oswaldo Cruz, responsável pelos planos de saneamento em busca da erradicação de doenças como a febre amarela, a peste bubônica e a varíola. As grandes reformas realizadas culminaram na revolta popular que ficou conhecida como A revolta da Vacina, em resposta à lei da Vacina Obrigatória, de 31 de outubro de 1904. A presença da redação da revista Rosa-Cruz na movimentada Praça Tiradentes talvez possa ser apontada como mais um dos fatores que contribuíram para o encerramento das atividades da revista. A Praça Tiradentes foi um dos diversos palcos das barricadas durante a Revolta da Vacina ${ }^{3}$. As reformas urbanas, as revoltas populares, os prejuízos financeiros, a debilitada saúde do diretor da revista foram os fatores determinantes para propagar na redação da revista Rosa-Cruz o Mal dos sete números. ${ }^{4}$

Mudou, também de acordo com a fase, a tipografia responsável pela impressão. Em 1901, a Tipografia do Instituto Profissional imprimiu os quatro números, com suas 162 páginas. E, em 1904, a Tipografia Leuzinger - a mesma que publicara o Catálogo da Exposição de História do Brasil, realizada pela Biblioteca Nacional do Rio de Janeiro, entre 1881 e 1882 - imprimiu os três fascículos, com suas 116 páginas.

Temos, portanto, a revista Rosa-Cruz organizada em:

\footnotetext{
${ }_{3}^{3}$ Para estudos mais aprofundados acerca da Revolta da Vacina sugerimos os trabalhos que aqui foram consultados: CARVALHO, José Murilo de. Sobre o pré-modernismo, 1988. Os bestializados, 1987. SANTOS, Joel Rufino. Quatro dias de rebelião, 1989. SEVCENKO, Nicolau. A revolta da Vacina, 1993.

${ }^{4}$ Atribui-se a Olavo Bilac a autoria da frase sobre o Mal dos Sete números. De acordo com Bilac, as revistas literárias padeciam desse mal, não conseguindo imprimir mais que o seu sétimo número. A revista Rosa-Cruz é um exemplo perfeito.
} 
N. I - Junho de 1901 - página 01 a 44.

N. Il - Julho de 1901 - página 45 a 90.

N. III - Agosto de 1901 - página 91 a 130.

N. IV - Setembro de 1901 - página 131 a 162.

Fasc. I - Julho de 1904 - página 01 a 44.

Fasc. II - Agosto de 1904 - página 45 a 76.

Fasc. III - Setembro de 1904 - página 77 a $116 .^{5}$

\section{A REVISTA ROSA-CRUZ E SEU ENTORNO}

Após exaustiva pesquisa ${ }^{6}$ nos acervos digitais de bibliotecas de várias universidades brasileiras, a saber, UFSC, USP, Unicamp, UNESP, UFRJ, UERJ, UFF, além do Portal de Periódicos, do Banco de Teses da Coordenação de Aperfeiçoamento de Pessoal de Nível Superior - CAPES e da Biblioteca do Itamaraty, o único estudo dedicado exclusivamente à Rosa-Cruz localizado é o livro de Antonio Dimas, Rosa-Cruz (contribuições ao Estudo do Simbolismo).

Há outros estudos que citam a revista, apontam sua marca na historiografia dos periódicos brasileiros, como o livro de Nelson Werneck Sodré, A história da Imprensa no Brasil. Sodré apresenta a revista, a situa na cronologia dos periódicos e cita os principais nomes colaboradores. Mesmo assim, a revista é apenas citada, tanto que o autor aponta Flávio da Silveira e Bernardes Sobrinho como alguns dos grandes colaboradores da revista ${ }^{7}$ quando, na verdade, ambos só publicaram uma vez em um universo de 131 colaborações. ${ }^{8} \mathrm{Um}$ sintoma de que

\footnotetext{
${ }^{5} \mathrm{~A}$ diferenciação entre números e fascículos é da própria revista.

${ }^{6}$ Essa pesquisa foi realizada pela busca através dos catálogos on-line das bibliotecas, dos portais e dos repositórios. Tal busca dividiu-se em: pelas palavras-chave "Rosa-Cruz", "Saturnino de Meirelles", "Revista Simbolista", "Revistas do início do séc. XX", "Simbolismo em Revista"; pelos anos de 1890 a 1910 como assunto, época ou data; por autores, testando todos os nomes dos autores publicados em Rosa-Cruz gerados pelo relatório geral de indexação. Assim, dentro dessa metodologia de pesquisa adotada, pois era necessário um corte, temos um universo de resultados. Aplicando o filtro "Rosa-Cruz" como assunto, como citação ou como referência, cheguei à lista de referências aqui adotada. Essa metodologia me permite pensar um universo de pesquisa e afirmar que, dentro desse universo, o que há é o que aqui está arrolado. E também me exime de haver outros estudos aqui não citados.

7 SODRÉ, Nelson Wernek. A história da imprensa no Brasil. Rio de Janeiro: Graal, 1977, p. 81.

${ }^{8}$ Situamos, aqui, este trabalho em sua origem. Fruto da dissertação de mestrado realizada sob orientação da professora doutora Maria Lucia de Barros Camargo, no NELIC, Núcleo de Estudos Literários e Culturais da UFSC. Como sustentação da argumentação, temos a indexação, primeira etapa de uma pesquisa realizada no núcleo, que, dentre tantas funções, nos permite reunir estatísticas sobre a revista, tais como número de colaborações, número de autores publicados, vocabulário controlado, organização dos artigos a partir de palavraschave, de autores, de temas.
} 
Sodré cita a revista a partir de outras referências, sem ter tido contato próximo com a produção.

Nessa desatenção não incorre Vera Lins, em seu Gonzaga Duque: a estratégia do franco-atirador. Em sua dissertação, Lins cita a revista Rosa-Cruz apenas para situá-la dentre as revistas simbolistas e afirmar que a Rosa-Cruz teve uma vida curta e a radical posição de não aceitar anúncios em suas páginas ${ }^{9}$, apesar de não elencar nenhum dos colaboradores.

Brito Broca também cita duas vezes a revista Rosa-Cruz, em seu A vida literária no Brasil - $1900 .{ }^{10} \mathrm{Na}$ primeira vez, apenas situa a revista dentre as outras revistas simbolistas e na segunda apresenta alguns detalhes, como datas de publicação, cidade, direção. Broca apresenta os nomes dos colaboradores e incorre no mesmo erro de Sodré, citando nomes como o de Mário Tibúrcio, o qual não publica na revista, e esquecendo-se de Castro Menezes, o quarto em número de colaborações, atrás somente de Saturnino de Meirelles, o diretor; de Cruz e Sousa, o homenageado; e de Luis Delfino.

Luciana Stegagno-Picchio, em seu História da Literatura Brasileira, também apenas elenca a revista Rosa-Cruz ao apresentar as revistas simbolistas brasileiras. ${ }^{11} \mathrm{O}$ mesmo fazem Ana Luiza Martins, em seu Revistas em Revista ${ }^{12}$ - acrescentando ser a revista Rosa-Cruz uma revista de escola, de movimento - e Massaud Moisés, em História da Literatura Brasileira - Simbolismo, o qual apenas menciona a revista ${ }^{13}$, sem apresentar nomes ou referências ao grupo.

Cassiana Lacerda Carollo, em seu Decadismo e Simbolismo no Brasil também cita a revista Rosa-Cruz, republicando trechos das cartas de Saturnino de Meirelles à Tavares Bastos, já publicadas no livro de Bastos de 1969. Mesmo sendo um volume unicamente dedicado ao simbolismo no Brasil, Carollo não

9 LINS, Vera. Gonzaga Duque: A estratégia do Franco-Atirador. Rio de Janeiro: Tempo Brasileiro, 1991, p. 56. Essa radical posição apontada por Lins merece atenção maior, uma vez que o fato de a revista Rosa-Cruz não possuir anúncios permite um desdobramento de pesquisa a fim de entender se a não existência de anúncio faz parte da proposta poética de "pureza" da arte ou se a revista Rosa-Cruz estava tão deslocada do mercado que não havia interessados em anunciar nela. Esse é mais um dos desdobramentos possíveis que queremos elencar nesse trabalho, mas que ficará como apontamento de pesquisa por não ser esse um dos objetivos deste artigo.

${ }^{10}$ BROCA, Brito. A vida literária no Brasil - 1900. Rio de Janeiro: José Olympio, 1975, p. 128 e p. 235.

${ }^{11}$ STEGAGNO-PICCHIO, Luciana. História da Literatura Brasileira. Rio de Janeiro: Nova Aguillar, 2004, p. 346.

12 MARTINS, Ana Luiza. Revistas em Revista. São Paulo: EdUSP, 2001, p. 144.

${ }^{13}$ MOISÉS, Massaud. História da Literatura Brasileira - Simbolismo. São Paulo: Cultrix, EdUSP, 1985, p. 18. 
apresenta a revista Rosa-Cruz de maneira adequada, afirmando inclusive que a revista possui somente seis números, quatro de 1901 e dois de $1904 .^{14}$

Em outros trabalhos historiográficos da literatura brasileira que tratam do simbolismo, a revista Rosa-Cruz sequer é citada, como, por exemplo, na Apresentação da Poesia Brasileira, de Manuel Bandeira, ou no De Anchieta a Euclides: Breve História da literatura Brasileira, de José Guilherme Merquior.

Do estudo de Dimas, desenvolvido como dissertação de mestrado, escrito em 1969 e defendido em 1970 ${ }^{15}$, podemos afirmar, portanto, ser o único exclusivamente sobre a revista Rosa-Cruz. E é o próprio Dimas quem nos apresenta seu trabalho:

\begin{abstract}
Esta pesquisa sobre o grupo simbolista reunido em torno de Rosa-Cruz [...] faz parte de um amplo projeto desenvolvido no Instituto de Estudos Brasileiros da Universidade de São Paulo, no sentido de se exumar periódicos literários, importantes para a compreensão mais apurada do desenvolvimento de nossa literatura. Dessa forma, depois de apresentar rapidamente dados técnicos sobre a publicação (direção, periodicidade, divisão interna, e feitio gráfico), nosso trabalho tenta reconstruir as origens do grupo, suas dificuldades e a dissidência final.
\end{abstract}

E o estudo se segue na análise das três categorias que Dimas propõe para pensar a revista: produção poemática, prosa poética, prosa não poética. É sintomático que Dimas tenha escolhido o termo exumar para referenciar o seu próprio trabalho. Se hoje nós temos um maior investimento na qualificação de acervos e arquivos, há 40 anos tínhamos condições precárias de reprodução de acervo. Exumar a revista Rosa-Cruz significa também dar a ela uma sobrevida, uma possibilidade de sobrevivência na historiografia de periódicos brasileiros, afinal, é graças à exumação de Dimas que hoje esse trabalho se faz possível. Exumar ultrapassa a dimensão do revirar o caput mortum para servir também como ferramenta de retorno à vida, retorno ao arquivo.

\title{
OBSERVANDO PÉTALAS
}

Diversos são os aspectos que provocam incômodos ou inquietações ao olhar a revista Rosa-Cruz, a começar pelo título. Se Dimas já cumpriu a tarefa

\footnotetext{
${ }^{14}$ CAROLLO, Cassiana Lacerda. Decadismo e simbolismo no Brasil. Rio de Janeiro: Livros Técnicos c Científicos, 1980, p. 215.

${ }^{15}$ Conforme nota na introdução do livro.
} 
de exumar a rosa, esse artigo pretende examinar esse caput mortum, seu conjunto e suas pétalas.

Não há, na revista, um grande projeto gráfico e uma elaborada estruturação dos textos. De maneira bastante sóbria, a publicação foi organizada a fim de dar destaque único aos artigos publicados. Isso significa que a revista RosaCruz não apresenta divisões internas em seções e mantém sempre a mesma ordem de publicação desde sua capa, seguida pelo sumário, pela folha de rosto e, por fim, pelo miolo. Não há seções de ensaios ou poemas. A sequência dos textos é definida de maneira arbitrária, não sendo possível estabelecer um modelo de ordenamento dos textos. Há algumas "coincidências", como a presença marcante de textos ou de Saturnino de Meirelles ou de Castro de Menezes exatamente subsequentes aos textos de Cruz e Sousa. Mas isso não é suficiente para criar um ordenamento para a revista completa. A revista também não apresenta uma contracapa ou uma página de encerramento. As poucas iconografias presentes na revista, um total de 04, servem sempre de apoio a um texto, sendo todas retratos dos autores cujos textos a iconografia ilustra, e todas assinadas por Mauricio Jubim.

Temos, portanto, algumas ligações entre a revista e diferentes ordens católicas ou maçônicas. A primeira delas é através do título Rosa-Cruz. A ordem Rosa-cruz ${ }^{16}$ é uma congregação que foi conhecida publicamente apenas no século XVII e cuja origem é controversa. Para alguns teóricos, a ordem está inserida em uma tradição esotérica ocidental, ligada principalmente a uma corrente do pensamento hermenêutico cristão, esse, por sua vez, relacionado por alguns à publicação de A divina comédia, de Dante. Para outros historiadores, a Ordem está relacionada com um grupo de protestantes alemães, entre os anos de 1614 e 1616, da ocasião de lançamento de três manifestos: Fama Fraternitatis $R$. C, publicado na cidade alemã de Kassel, em 1614; Confessio Fraternitatis Rosae Crucis, publicado na mesma cidade, um ano após; e Núpcias Alquímicas de Christian Rozenkreuz ano 1459, publicado em Estrasburgo, em 1616. A historiadora Frances Yates $^{17}$, por exemplo, observou a grande influência desses textos no período, intitulando-o de lluminismo Rosa-cruz.

\footnotetext{
${ }^{16}$ Atualmente, o maior centro da Ordem Rosa-cruz no Brasil está localizado em Curitiba, Paraná. Essa "pequena coincidência" de estar situada em um centro de forte presença do simbolismo no Brasil mereceria estudos mais aprofundados.

17 YATES, Frances. O lluminismo Rosacruz. São Paulo: Cultrix, 1983.
} 
A Ordem Rosa-cruz teria sido fundada por Chistian Rosenkreuz, um personagem mítico, cuja existência nunca foi comprovada. Alguns historiadores apontam que Rosenkreuz era apenas uma lenda, usada metaforicamente para explicitar os princípios e crenças da ordem. Em sua história, conta-se que, nascido em 1378, na Alemanha, Christian iniciou sua educação aos quatro anos, em uma abadia, na qual teria aprendido grego, latim, hebraico e magia. Após longa visita a países como Egito, Marrocos, Chipre teria retornado à Alemanha em 1407 e fundado a ordem Rosa-cruz de acordo com os ensinamentos acerca do ocultismo obtidos com seus mestres árabes. Depois, teriam fundado a Casa Sancti Spiritus, na qual desenvolveram-se os trabalhados da fraternidade. Segundo o texto Fama Fraternitatis, Rosenkreuz teria falecido em 1484. O nome mais familiar dentre os membros conhecidos da Ordem é o de Francis Bacon, o qual teria ocupado o cargo máximo, o de Imperador, na organização. Alguns boatos o ligam à autoria dos três textos-manifestos.

Uma das maneiras de verificar se a proximidade da revista Rosa-Cruz com a ordem Rosa-Cruz se dá apenas por seu título ou se está também nos seus textos e posições é cotejar os princípios da Ordem com as ideias e estéticas relacionadas na revista. A filosofia rosa-cruz pode ser definida, grosso modo, como uma defesa da fraternidade universal entre todos os homens. Segundo as crenças da Ordem, os homens podem desenvolver suas potencialidades para tornarem-se melhores, mais sadios e felizes. Os pilares das ações da Ordem são o autoconhecimento e a manifestação da real natureza espiritual. E sua trindade pode ser explicitada pelos verbos sentir, pensar e agir, na busca pela constante evolução humana rumo à pureza espiritual e à paz total.

Esses princípios podem ser lidos em alguns dos textos publicados na revista Rosa-Cruz, como, por exemplo, o soneto de Carlos D. Fernandes, A voz das Origens, do primeiro número de 1901:

A VOZ DAS ORIGENS

Todo ser, que nos círculos da Vida

Girando em convulsões e ânsias palpita,

Aspira à placidez indefinida

Da celeste mansão que o sonho habita.

Toda a alma que os anima foi proscripta

D'essa eterna região desconhecida,

De cuja natureza, em vão cogita

O esforço da razão sempre vencida. 
Da ave que voa ao verme que rasteja,

Em todo ser, por ínfimo que seja.

Há um secreto desejo de ascendência.

Há um vago desejo que os embala,

Uma voz inefável que lhes fala

De um outro modo de ser n'outra existência. ${ }^{18}$

No soneto de Fernandes, os princípios rosacruzeanos estão mais que expostos, estão ampliados da esfera humana para a esfera animal, da ave ao verme. Sempre o desejo de ascendência, de evolução - na qual a razão é sempre vencida - de atingir outra existência, ascender à celeste mansão onírica, sempre o desejo de imenso prazer a falar a voz das origens. Porém, essa possibilidade de ascensão é sempre reservada aos poucos de espírito sensível e evoluído, cabendo, aos mortais, o mundo inacessivel:

\section{MUNDO INACESSÍVEL}

Tu'alma lembra um mundo inacessível

Onde só astros e águias vão pairando

Onde se escuta, trágica, cantando,

A sinfonia da Amplidão terrível!

Alma nenhuma, que não for sensível, Que asas não tenha para as ir vibrando, Essa Região secreta desvendando,

Falece, morre, n'um pavor incrível!

É preciso ter asas e ter garras

Para atingir aos ruídos de fanfarras

Do mundo da tu'alma augusta e forte.

É preciso subir ígneas montanhas

E emudecer, entre visões estranhas,

N'um sentimento mais sutil que a Morte! ${ }^{19}$

Alma nenhuma que não seja sensível, que não parta do princípio da trindade rosacruzeana de sentir, pensar e agir conseguiria vencer, abrir os caminhos dentre montanhas ígneas e os estranhos delírios a fim de alcançar os mundos

18 FERNANDES, Carlos D. A voz das origens. Rosa-Cruz, n. 01, 1901, p. 11.

19 SOUSA, Cruz e. Mundo inacessível. Rosa-Cruz. n. 01, 1901, p. 29 - 30. 
inacessíveis de uma região secreta. Vale notar que os vínculos dos textos publicados na revista com a Ordem estão desde os novos - no caso, Carlos D. Fernandes que contava com 26 anos em 1901 -, até os textos selecionados de Cruz e Sousa.

Podemos, portanto, elencar diversos textos publicados em todos os números da revista que partilham de alguma correspondência - e vale destacar que essa correspondência é de leitura, ou seja, é uma correspondência de entrada no arquivo e não uma ligação que necessariamente está declarada na revista para com a Ordem Rosa-cruz. Dentre os textos que podem ser destacados elencamos:

\section{O MESTRE}

(Nuvens e Raios)

Nas tardes de janeiro, o sol no occaso, á beira

Do mar inquiéto, e ondeando á doce luz do poente,

Parava Elle de olhar as vezes de repente,

Como alguem que arfa e cai em meio da carreira.

Cégo e surdo ao rumôr da natureza inteira,

Na pallidez mortal de um marmore indifferente,

Parecia ter ido, onde não vai a gente,

Onde jamais chegou vôo d'águia altaneira.

Como quem surge após de um abysmo, trazia

Nesgas d'alva cantante, e pedaços de dia

No olhar, na fronte; e um pouco em si de cinza e lava. -

E nós: Mestre, por lá o que de nôvo achaste?

E Elle erécto, bem como a flor em cima da haste:

- Vi Prometheu no fim do céu: inda o escalava!... - 20

Como quem surge após de um abismo, Rosenkreuz retorna de suas peregrinações em países árabes tendo avistado Prometeu, o responsável, de acordo com a mitologia, por dar aos homens o fogo dos deuses. Contamos ainda com os sonetos Grandeza Oculta ${ }^{21}$, de Cruz e Sousa; além dos três sonetos que compõem a sequência Rosas Mysticas ${ }^{22}$, de Gonçalo Jacome.

${ }^{20}$ DELFINO, Luiz. O mestre. Rosa-Cruz, f. 03, 1904, p. 82.

${ }^{21}$ SOUZA, Cruz. Grandeza Oculta. Rosa-Cruz, f. 01, 1904, p. 06.

22 JACOME, Gonçalo. Rosas Mysticas. Rosa-Cruz, f. 01, 1904, p. 13-14. 
Recuperando a análise diplomática da revista, nas páginas internas pares apresenta-se a numeração em posição superior esquerda e o título da revista com a palavra ROSA em maiúsculas, hífen, e a Cruz de Cristo

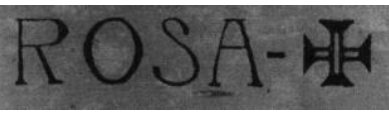

Cruz de Cristo - imagem do miolo da revista na posição superior direita, conforme a figura. Nas páginas internas ímpares, as posições se invertem. Porém, essas informações não aparecem em todas as páginas, sem uma lógica aparente, o que nos leva à se-

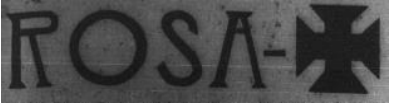

Cruz Pátea imagem da capa da revista gunda ligação da revista Rosa-Cruz com ordens católicas ou maçônicas. Se o título pode estar ligado à Ordem Rosa-cruz, as escolhas por cruzes específicas nos remetem à Ordem de Cristo ou Ordem dos Cavaleiros de Cristo. Colocar tanto a Cruz Pátea - uma subcategoria da Cruz de Cristo - na capa, quanto a Cruz de Cristo nas páginas internas pode ser entendido como uma ligação explícita, uma vez que a opção por um tipo específico de cruz em detrimentos de todos os outros é sintomática.

A Ordem de Cristo é uma ordem militar e religiosa, criada em 14 de março de 1319 pela bula papal Ad ea ex-quibus, de João XXII, organizada a fim de substituir a Ordem dos Templários, depois dos sucessivos fracassos nas cruzadas católicas ao oriente. A extinção da ordem deu-se em 1834, ao final da Guerra Civil Portuguesa. Pelas fortes ligações não somente entre os princípios éticos e filosóficos da Ordem, mas também pelos sistemas de hierarquia e estruturação, a Ordem de Cristo está relacionada com o surgimento da maçonaria. Dentre os membros da Ordem Militar estão Bartolomeu Dias, o primeiro navegador europeu a dobrar o Cabo da Boa Esperança; Fernão de Magalhães, o primeiro navegador europeu a alcançar a Terra do Fogo; Infante D. Henrique, uma das figuras centrais das grandes descobertas da navegação portuguesa; assim como o também navegador Vasco da Gama. Por sua origem comum para com a maçonaria - na Ordem dos Templários, muitas são as suspeitas de que a Ordem de Cristo foi extinta por estar mais ligada aos movimentos maçônicos do que à própria igreja católica.

Assim, a escolha de dois tipos específicos de cruz não parece gratuita e aponta possíveis ligações, afiliações da revista com movimentos místicos e religiosos. 


\title{
O CÃO E SEUS FRASCOS - OU AINDA, DA MACERAÇÃO DE PÉTALAS, PERFUME
}

O aviso em caixa-alta presente na folha de rosto, nomeando Saturnino de Meirelles como Diretor da Revista, reforça o depoimento de Andrade Muricy a Antonio Dimas, no qual o autor de Panorama do movimento...afirma que

\begin{abstract}
No que se refere à organização, a organização de Rosa-Cruz era Saturnino de Meirelles. Era um moço de um desvelo, de uma dedicação prodigiosa. Filho de um pai, que era um dos maiores clínicos do Rio de Janeiro e tinha o mesmo nome do filho: Dr. Saturnino de Meirelles. O pai lhe dava certos recursos, poucos, e ele trabalhava, gastava tudo com Rosa-Cruz. A organização, praticamente, era ele. ${ }^{23}$
\end{abstract}

Era ele, Saturnino, o nome forte da revista Rosa-Cruz. E por ser uma revista de um grupo, com um poeta à sua frente, é de se estranhar que a revista RosaCruz não tenha publicado editoriais ou um "A que se deve" a fim de defender suas posições ou dizer a que veio. É de se estranhar porque essa era uma prática comum nos periódicos e revistas da época, como aponta Ana Luiza Martins, em Revistas em Revista:

\begin{abstract}
suprindo uma lacuna era a chamada de apresentação recorrente nas revistas paulistas da virada do século, mas, não só. Tudo dependia do teor da publicação. Se jocosa, o cavaco preliminar era de rigor; se dinâmica, atenta à "velocidade" daqueles novos tempos, o duas palavras bastava para dizer a que vinha; se solene, um compenetrado a que se deve introduzia o primeiro número. No geral, todos esses artigos de fundo nada mais eram que o "narcótico habitual com que se entretêm o leitor", de acordo com a apresentação da revista A Borboleta, de 1899. ${ }^{24}$
\end{abstract}

Porém, é possível delinear possíveis leituras, posições e "editoriais" nos textos, nas opções, nas escolhas que Saturnino faz, tanto na ordem de publicação dos textos, como na escolha das contribuições estrangeiras, nenhuma feita para a revista, todas arbitrariamente selecionadas.

O texto que abre o primeiro número da revista Rosa-Cruz, de 1901, já na página 04, é um pequeno poema em prosa de Baudelaire, publicado em francês,

\footnotetext{
${ }^{23}$ Depoimento de Andrade Muricy a Antonio Dimas, em resposta ao questionamento "Num plano mais específico, quais os dados de que o Sr. dispõe a respeito de Rosa-Cruz: organização, circulação, projeção, realização, hegemonia do grupo etc.?" Rosa-Cruz. 1980, p. 132.

${ }^{24}$ MARTINS, Ana Luiza. Op. cit., 2001, p. 16. [Grifos da autora].
} 
intitulado Le chien et le flacon. Ao se oferecer um frasco do melhor dos perfumes ao cão, a reação é de asco; mas ao se oferecer

Un paquet d'excréments, vous l'auriez flairé avec délices et peut-être dévoré. Ainsi, vous-même, indigne compagnon de ma triste vie, vous ressemblez au public, à qui il ne faut jamais présenter des parfums délicats que l'exaspèrent, mais des ordures soigneusement choisies. ${ }^{25}$

Eis o que pode ser lido como um editorial que diz, sem meias palavras, "a que se deve" a revista Rosa-Cruz, cujo objetivo é apresentar os melhores perfumes aos melhores narizes. O que nos faz perceber que o público que a revista Rosa-Cruz pretendia atingir é pequeno, restrito e não o suficiente para gerar lucro com vendas ou assinaturas da revista. Esse pode ser apontado como um dos motivos que encurtaram a vida da revista.

Em carta enviada a Tavares Bastos, datada de 01 de agosto de 1904, Saturnino de Meirelles solicita ao jovem poeta "o trabalho e os $20 \$$ que prometeste. Já estou cansado e me sinto cada vez mais só no meio da luta. Quero dar a revista $[. .$.$] e, no entanto, falta-me dinheiro. Só posso contribuir com 100 \$$. [...] E a venda diminuiu muito, talvez não chegue a $70 \$ " .{ }^{26}$ Esse número referido por Meirelles nem chegou a ser editado, pois a crise já estava deflagrada. Desde o primeiro número, para editar a revista, Meirelles cobrava contribuições dos interessados a publicar, arcando ele com os maiores custos, como se percebe pela carta. Como não havia anúncios e a vendagem não dava retorno nem ao próprio diretor, o prejuízo era, portanto, maior a cada número. Se todos os números fossem vendidos a valores nacionais, de 500 , para atingir os $70 \$$ referidos na carta, bastariam vender 140 exemplares da revista. Ou seja, o público

25 BAUDELAIRE, Charles. Le chien et le flacon. Rosa-Cruz, n. 01, 1901, p. 04. Transcrevo a tradução completa de Leda Tenório da Mota:

O cão e o frasco

"Meu belo cão, meu bom cão, meu querido totó, aproxime-se e venha respirar um excelente perfume comprado no melhor perfumista da cidade."

E o pobre cão, mexendo o rabo, o que é, acho, nesses pobres seres, o sinal correspondente ao riso e ao sorriso, aproxima-se e curiosamente pousa o úmido nariz no frasco aberto; depois, subitamente recuando de pavor, late para mim, à guisa de reprovação.

"Ah miserável cão, se lhe tivesse oferecido um embrulho de excrementos o teria farejado com delícia e talvez devorado. Assim, até você, indigno companheiro de minha triste vida, se parece com o público, a quem nunca se devem apresentar perfumes delicados que 0 exasperem, mas somente imundícies cuidadosamente escolhidas." BAUDELAIRE, Charles. Spleen de Paris. Rio de Janeiro: Imago, 1995, p. 31.

${ }^{26}$ MEIRELLES, Saturnino de. Carta VIII 01 de agosto de 1904. In: BASTOS, Cassiano Tavares. $O$ simbolismo no Brasil e outros escritos. Rio de Janeiro: São José, 1969, p. 23. 
leitor era diminuto. E com Saturnino doente, desempregado, sem apoio do grupo, a revista Rosa-Cruz estava fadada ao fim.

Os indícios que corroboram com a leitura do pequeno poema em prosa de Baudelaire como editorial são diversos. A começar pelo próprio nome da revista, afinal, a palavra Rosa-Cruz pode não fazer referências somente a misticismos ou ordem religiosas, ao contrário do que aponta Tavares Bastos, mas sim também ser uma composição muito bem engendrada de Rosa - perfume, Cruz e Sousa, levando ao extremo sua função de homenagem ao Dante Negro. Se levarmos em conta que o primeiro texto de Cruz e Sousa publicado, o segundo na ordem, intitula-se Flor sentimental, temos ainda mais indícios que fortalecem a hipótese do nome composto para a revista. ${ }^{27}$

Portanto, é sintomático também que - a corroborar a função homenagem assumida pela revista, nas palavras de Tavares Bastos - dos 16 textos de Cruz e Sousa publicados, 08 sejam precedidos ou sucedidos por textos de Saturnino de Meirelles. E não por mera coincidência, afinal, os títulos e temas dos textos do diretor da revista também são de homenagem, por exemplo, os sonetos $O$ eterno guia, $O$ supremo ser e $O$ acordar da alma, publicados nos números 01,03 de 1901 e número 02 de 1904, respectivamente.

Essa percepção só nos foi possível através da realização da indexação da revista, uma vez que foram os relatórios, estatísticas e listagens de textos e autores - como os índices absolutos de autores e publicações - que nos "fizeram" ver as diferentes funções possíveis dentro da revista.

Outros indícios dessas funções assumidas pela revista, ou melhor, presumidas à revista, podem ser observadas a partir dos números absolutos e percentuais de publicação, listados na Tabela 1:

Tabela 1 - Lista geral de autores

\begin{tabular}{|l|c|c|}
\hline \multicolumn{1}{|c|}{ Autores } & Número Absoluto & Número Percentual \\
\hline \hline ALENCAR,Cabral de & 2 & 1,53 \\
\hline AMARAL,Amadeu & 1 & 0,76 \\
\hline ANDRÉA,João & 1 & 0,76 \\
\hline ARAÚJO,Paulo & 3 & 2,29 \\
\hline BARREIRA,João & 2 & 1,53 \\
\hline
\end{tabular}

27 Outro dos tantos indícios de que o pequeno poema em prosa de Baudelaire pode ser lido como um editorial é o fato de que é o único texto nos sete números da revista que não consta no sumário. Ou seja, aparece praticamente como um editorial, uma abertura para a proposta da revista. 


\begin{tabular}{|c|c|c|}
\hline BARROS, Rafaelina de & 3 & 2,29 \\
\hline BARROSO,Colatino & 1 & 0,76 \\
\hline BASTOS,Cassiano Tavares & 5 & 3,82 \\
\hline BAUDELAIRE,Charles & 1 & 0,76 \\
\hline BIGEON,Maurice & 2 & 1,53 \\
\hline CARNEIRO,Mário & 2 & 1,53 \\
\hline CORBIÈRE,Tristan & 1 & 0,76 \\
\hline DELFINO,Luís & 11 & 8,40 \\
\hline FERNANDES, Carlos Dias & 9 & 6,87 \\
\hline GÓES,Carlos & 2 & 1,53 \\
\hline GOMES,Roberto & 1 & 0,76 \\
\hline GUIMARAENS, Alphonsus de & 5 & 3,82 \\
\hline GUIMARAENS,Archangelus de & 1 & 0,76 \\
\hline JACOME,Gonçalo & 3 & 2,29 \\
\hline JUBIM,Maurício & 4 & 3,05 \\
\hline LAUTRÉAMONT, Conde de & 1 & 0,76 \\
\hline MAETERLINCK,Maurice & 2 & 1,53 \\
\hline MALAGUTI,Heitor & 2 & 1,53 \\
\hline MALLARMÉ,Stéphane & 1 & 0,76 \\
\hline MEIRELLES, Saturnino de & 13 & 9,92 \\
\hline MELO,Miguel & 1 & 0,76 \\
\hline MENEZES,Álvaro de Castro & 10 & 7,63 \\
\hline NIETZSCHE,Friedrich & 1 & 0,76 \\
\hline PACHECO,Félix & 9 & 6,87 \\
\hline PÉLADAN, & 1 & 0,76 \\
\hline POMBO, Rocha & 4 & 3,05 \\
\hline POMPÉIA,Raul & 1 & 0,76 \\
\hline RIMBAUD, Arthur & 2 & 1,53 \\
\hline SILVA,Pereira da & 5 & 3,82 \\
\hline SILVEIRA,Flávio da & 1 & 0,76 \\
\hline SOBRINHO,Bernardes & 1 & 0,76 \\
\hline SOUSA,Cruz e & 16 & 12,21 \\
\hline Totais & 131 & 100,00 \\
\hline
\end{tabular}


A partir da lista de autores e das estatísticas geradas pelo sistema de indexação, podemos organizar os colaboradores da revista Rosa-Cruz em quatro grupos. O primeiro, o grupo dos estrangeiros, cujas contribuições são escolhidas propositadamente para complementar as edições da revista e cuja presença contribui no mapeamento de referências e leituras da revista: João Barreira, Charles Baudelaire, Maurice Bigeon, Tristan Corbière, Conde de Lautréamont, Maurice Maeterlinck, Stéphane Mallarmé, Friedrich Nietzsche, Sar Péladan e Arthur Rimbaud. O grupo dos estrangeiros é composto por 10 nomes e responde por 14 textos publicados, em um percentual de 10,68 de todos os textos da revista Rosa-Cruz.

$\mathrm{Na}$ contramão, Tavares Bastos afirma que:

\begin{abstract}
A Rosa-Cruz não publicava anúncios. Não parecia nisso com as correligionárias de estética. Numa das efêmeras revistas que precederam a Rosa-Cruz não era assim. Só se fazia arte, e arte simbolista. Cruz e Sousa era conservado como um Deus tutelar da publicação. Dos consagrados [dentre os da época] Luiz Delfino era o único que Ihes merecia consideração. Tudo mais nada valia: "fósseis e desonestos", na vossa classificação de então. Quando faltava matéria, transcreviam-se trechos de Nietzsche, Paul Adam², Mallarmé, reproduziram-se rimas dos "poetas malditos". 29
\end{abstract}

A afirmação de Tavares Bastos pode ser aqui refutada por percebermos, como se deu no texto de Baudelaire, que as contribuições estrangeiras possibilitam uma leitura das seleções, propostas e desejos do grupo RC, ao editar a revista e não são um simples "tapa buracos" na falta de matérias para as edições.

Organizamos o segundo grupo de autores publicados na revista sob a alcunha de trio: Alphonsus de Guimaraens, Luis Delfino e Cruz e Sousa. Esse é o grupo dos nomes consagrados pelo grupo RC que muito os admirava e também atualmente pela crítica literária em geral. Luis Delfino era o único nome de fora do conjunto de poetas simbolistas que merecia deles alguma consideração, ainda de acordo com Tavares Bastos. O consagrado trio é o que mais publica, na relação texto por autor, sendo apenas 03 nomes e correspondendo a um total de 32 textos ou 24,43\% das contribuições. Metade delas, 16 ou 12,21\% de Cruz e Sousa.

28 Deve-se ler pelo pseudônimo de Sar Péladan, e não Paul Adam.

29 BASTOS, C. Tavares. Como surgiram os místicos de "Rosa-Cruz". O simbolismo no Brasil e outros escritos. 1969, p. 9. 
O terceiro grupo, o dos menores, contém os nomes já estudados pela crítica específica do simbolismo no Brasil: Álvaro de Castro Menezes, Amadeu Amaral, Archangelus de Guimaraens, Cabral de Alencar, Carlos Dias Fernandes, Cassiano Tavares Bastos, Colatino Barroso, Félix Pacheco, Flávio da Silveira, Gonçalo Jacome, Maurício Jubim, Rocha Pombo, Raul Pompéia, Paulo Araújo, Pereira da Silva e Saturnino de Meirelles. Com um total de 72 textos, e um percentual de $54,96 \%$ das contribuições, o grupo dos menores é o grupo dominante na revista, uma vez que "os demais colaboradores [o grupo dos 'menores'], pouco mais de meia dúzia, concorriam com $50 \$$ por mês para a publicação, que sempre dava déficit; $50 \$$ mensais tirados de ordenados de repórteres ou da mesada de estudantes, calcula-se bem o sacrifício". ${ }^{30}$ Ou seja, era esse o grupo responsável pelo custeio da revista, afinal, como já vimos, a revista RosaCruz era deficitária: cobrava-se dos autores uma colaboração, mas Meirelles ficava com a fatia maior da dívida.

O quarto e último grupo que compusemos é o dos desconhecidos, aqueles sem fortuna crítica consolidada à época - e muitos, senão todos, ainda hoje: Bernardes Sobrinho, Heitor Malaguti, João Andréia, Carlos Góes, Mário Carneiro, Miguel Melo, Rafaelina de Barros e Roberto Gomes. Esse grupo responde por 13 textos, 9,93\% do total. Os nomes que circulam no que chamamos de quarto grupo, o grupo dos desconhecidos, ou não aparecem nas diversas referências anteriormente elencadas, ou aparecem muito en passant, sem quaisquer informações seguras o suficiente para serem creditadas. Acerca de Miguel Melo, por exemplo, a única informação localizada foi fornecida por Brito Broca, em seu $A$ vida literária, ao afirmar que Melo era funcionário da Biblioteca Nacional. Nada mais que isso.

A divisão e os totais de contribuição dos grupos levam a crer que a revista Rosa-Cruz atuou na dupla mão de homenagear o trio, principalmente Cruz e Sousa, o maior colaborador absoluto da revista, com 16 entradas, e de, ao mesmo tempo, lançar as premissas dos "novos" simbolistas, o grupo dos menores. Novos não apenas por terem em Rosa-Cruz o primeiro veículo de publicação de seus textos, publicando na revista materiais inéditos - em alguns casos até hoje -, mas por suas idades propriamente ditas. Tavares Bastos, por exem-

\footnotetext{
30 Ibidem, p. 9.
} 
plo, contava com 15 ou 16 anos em 1901. Paulo Araújo e Castro Menezes contavam com 18 ou 19 anos. Félix Pacheco ${ }^{31} 22$ ou 23, Saturnino de Meirelles 23 ou 24 anos.

A presença do quarto grupo, hoje tido como desconhecido, pode ser mesclada ao grupo dos menores que, por motivos desconhecidos, não se mantiveram ligados à produção literária, ou tiveram sua produção totalmente dispersada pelo tempo, como ocorreu com o acervo deixado por Félix Pacheco à Biblioteca Municipal Mário de Andrade ${ }^{32}$. E o grupo dos estrangeiros nos permite apontar as referências e as leituras dos responsáveis pela seleção e publicação dos textos da revista.

Propusemos, assim, nesse artigo, uma outra possibilidade de leitura desse caput mortum da revista Rosa-Cruz, apresentando a revista e organizando a partir de quatro grupos de autores diferentes em suas páginas. Outras possibilidades ainda se abrem se, por exemplo, ao invés de organizarmos os grupos a partir dos autores publicados pela revista, organizarmo-los a partir da temática dos textos, ressignificando a proposta de Antonio Dimas de trabalhar com os eixos da produção poemática, prosa poética e prosa não poética. Guardemos, porém, essa proposta para um artigo futuro.

Recebido em: 29 de outubro de 2016 Aceito em: 6 de dezembro de 2016

31 Félix Pacheco é bastante conhecido pelas suas atividades políticas, sendo eleito Deputado Federal pelo Piauí, em 1909, reeleito até 1921, quando entrou para o Senado Federal. Foi ministro das Relações Exteriores no governo de Artur Bernardes, eleito para a Academia Brasileira de Letras em 1912, além de ter sido o pioneiro da introdução do método de identificação datiloscópica no Brasil, dando nome ao Instituto de Identificação Félix Pacheco, no Distrito Federal, o primeiro a ter um banco de dados de identificação datiloscópica no Brasil.

32 Andrade Muricy afirma, em seu já citado depoimento a Antonio Dimas, que o acervo de Félix Pacheco, doado à Biblioteca Mário de Andrade, em São Paulo, não foi catalogado e com o tempo se perdeu. Hoje, segundo ele, não é possível determinar quais documentos ou obras pertenciam a Pacheco. DIMAS, Antonio. Rosa-Cruz, 1980, p. 133. Em pesquisa através do site da Biblioteca Mário de Andrade, conferimos a informação de que o acervo de Pacheco está lá depositado e a identificação de quais obras pertenciam ao acervo não é possível por não ter sido feita a devida catalogação à época da aquisição. 